\title{
The model of the organizational and technical weapons and military equipment recovery system
}

\author{
Vladimir Kotsiuruba ${ }^{1}$ A; Vladimir Dachkovskyi * 2 A; Tymur Kurtseitov ${ }^{3}$ A \\ A National Defense University of Ukraine named after Ivan Cherniakhovskyi, Kyiv, Ukraine
}

Received: December 10, 2021 | Revised: December 25, 2021 | Accepted: December 30, 2021

DOI: $10.33445 / s d s .2021 .11 .6 .15$

\begin{abstract}
Analysis of wars and armed conflicts in recent years and the performance of tasks by military units (subunits) in a United Forces operation (anti-terrorist operation) confirms that the success of the troops (forces) in performing tasks will depend on the performance of the logistics system. The availability of military units with serviceable weapons and military equipment (WME) ensures the fulfillment of the mission and the advantage over the enemy.

At the same time, the timeliness of providing military units (subunits) with serviceable weapons and military equipment depends on the efficiency of the logistics system, namely, on the recovery subsystem, which is its component.

However, as studies have shown, there is currently insufficient sufficiency of the recovery system. All this is related to the definition of the composition of forces and means and the structure of the WME recovery system at different levels of the hierarchy.

Therefore, in the article it is considered that for the WME recovery system, the main parameter is the allowable time of WME recovery, differentiated by levels of complexity of tasks. Determination of this parameter for the basic variant of construction of WME recovery system is proposed using the average indicator of intensity of the flow of possible volumes of tasks on the WME recovery.

To determine the rational structure of WME recovery system and to calculate its main parameters the combined method of optimization of WME recovery system was used. Containing two stages: on the first - based on the requirements to the permissible terms of WME recovery system, the rational structure of the recovery system is defined, and on the second using the method of statistical modeling, the parameters of the structure and composition of forces and means of the WME recovery system at each level of the hierarchy are defined.
\end{abstract}

Key words weapons, equipment, modelling, recovery, maintenance, hierarchy, intensity.

\section{Introduction}

Every year, for the successful performance of tasks by troops (forces), military formations receive more effective means of destruction of weapons and military equipment (WME).

The analysis of the use of troops (forces) has repeatedly confirmed that success in carrying out tasks in an operation (combat operations) depends not only on the tactics of combat operations, but also on the timely, high-quality support of military units (subunits)
(Dachkovskyi, V., 2020; Kotsiuruba, V. Dachkovskyi V., 2020). After all, the timely provision of military units with materiel, hightech types of WME, etc., prefers the enemy and ensures the presence of military units in combat-ready condition (Dachkovskyi, V.O., $2020^{\mathrm{b}}$ ). However, the adoption of high-tech types of WME requires timely and high-quality implementation of measures for the maintenance and restoration of WME that have

\footnotetext{
${ }^{1}$ Dr. Technical Sciences, Professor, Professor of the Department, e-mail: kotcuru@ukr.net, ORCID: 0000-0001-6565-9576

${ }^{2}$ Corresponding author: Candidate of Technical Sciences, Associate Professor, Associate Professor of the Department, e-mail: 1903vova@ukr.net, ORCID: 0000-0003-1480-5021

${ }^{3}$ Dr. Technical Sciences, Professor, Head of the Department, e-mail: kurttimur@ukr.net, ORCID: 0000-0001-6478-6469
} 
been damaged in combat or failed for technical reasons.

The experience of wars and armed conflicts, the conduct of operations of the United Forces in the territory of Donetsk and Luhansk regions showed that the success in the performance of tasks by military units (subunits) in the conduct of hostilities will depend on the efficiency of the functioning of the system of recovery of WME, which is one of the functions of the logistics system of the Armed Forces of Ukraine

In recent years, research into the functioning of the maintenance and recovery system of WME has become more and more relevant (Dachkovskyi, V., 2020a; Kotsiuruba, V.
Dachkovskyi V., 2020; Dachkovskyi, V.O., 2020 $)$. Thus, untimely recovery of damaged types of WME can lead to a lower level of combat effectiveness of military units (subunits), and in some cases to a complete loss of combat effectiveness and, ultimately, to a failure in the performance of tasks in operations (combat operations). This, in turn, leads to the loss of personnel, loss of WME and changes in the operational environment, which makes it impossible to perform the mission.

Therefore, issues related to the modeling of organizational and technical systems regarding the functioning of the recovery system of WME are quite relevant and require ongoing research.

\section{Material and methods}

A number of studies are focused on the research of the recovery of the WME and the provision of material means but these studies do not provide an opportunity to simulate the process of functioning of the WME recovery system. In particular, in the work (Nestorenko A., 2014) an analysis of inventory management models is provided. Improved mathematical models with compensated deficits and certain conditions for their service request under different variants of basic information. Some of the issues of material means provision are considered in the work (Kucheruk O.O., Polyakov A.P.), where the types of military road transport, their advantages and disadvantages are considered. Partial processing of this problem is also considered in the publication (Bondarenko O.G., Tovma L.F., Nesterenko R.V., Kasim O.G., 2018), which proposes the main directions of logistics support and proposed definitions and the main components, principles and functions of logistics support in modern conditions. It is mentioned that logistics support should be based on principles in accordance with national and international standards of security and defense. And in the work (Bilous M.V., Shmatenko O.P., Galan O.V., 2020) it is reviewed that outsourcing should be treated as one of the main logistics strategies, which is used in many aspects of logistics activities. The need to develop a legal framework standardizing the interaction between the Ministry of Defense of Ukraine and outsourcing and the need to develop standards for the provision of logistics outsourcing services have been identified. In the work (Dyptan V., Tykhonenko O., Pavlenko S., 2020), an approach to evaluating the effectiveness of providing material means for the actions of military parts of the Armed Forces of Ukraine was proposed. This approach makes it possible to determine the ability of units to provide material means, taking into account their authorized number of personnel, and in the work (NATO) the strategic concept of the North Atlantic Alliance, the general political principles and structure, the basic principles of logistics support, and the organizational structure are considered. In the paper (Zalevsky G., Lekakh A., Gurin O., Startsev V., Kalachova V., 2019) proposed indicators and criteria for evaluating the effectiveness of the performance of tasks of logistic support of military units. Suggestions for the use of the proposed indicators and relevant criteria are presented, and in the work (Zvonko, A., Ovcharenko, I., Yaroshenko, A., \& Pavlov, D., 2021) identified the need to improve existing and search for new ways to perform logistical support tasks, in particular the recovery of damaged WME models. A methodology for 
determination of the capabilities of repairrestoration bodies to search for damaged WME samples has been proposed. Also, the processing of this issue was presented in the paper (Saleh Alyahya, Ashit Kumar Dutta, 2020), which determined that the use of modern technology provides opportunities for automation of identification and management of information flows. These technologies provide a solution to the problems associated with logistics management. Information gathering requires more efficient solutions for processing such amount of data. The use of fuzzy logic for fuzzy data processing to process such data and get better results has been proposed, and in the work (Sampir, O., 2021) improved the methodology for evaluating the system of recovery of WME of a separate mechanized brigade, which takes into account the possibility and intensity of received damaged WME samples and allows to determine the repair capabilities of repair and recovery units, with the consideration of personnel losses. In the work (Dachkovskyi, V., 2021) a methodology for evaluating the efficiency of logistics operations is proposed, in which the first stage defines the initial data, the second stage presents the hierarchy of the logistics system with the subsystems of control bodies, compositions, recovery of WME, provision of material means, etc. Priority technical means that are used to perform logistics operations are defined. At the third stage, the forces and methods of logistics are rationally allocated to provide military parts in a timely manner with materiel. At the fourth stage a rational route of maneuvering by technical means in the performance of the task is defined, and at the fifth stage a comparative analysis and evaluation of technical means, which are involved in the performance of logistic operations, is carried out. In the paper (Kotsyuruba, V., Sivak, V., \& Uhrynovych, O., 2021) it is defined that the criterion for achieving the goal set by the recovery system is a given number of operating WME in service at the end of the operation, and the criterion for performing tasks at the levels of the hierarchy is defined as the effectiveness of the recovery of WME. Some aspects of this problem are outlined in the paper (Kondratyuk, I., 2021), which analyzes the development of mobile means of maintenance and repair of military vehicles, and the work (Sampir, O., 2021) is devoted to improving the methodology for determining the technical reconnaissance capabilities of damaged WME samples in the course of combat operations. The work (Better, M. Glover, F. Laguna M., 2007) is devoted to finding the optimal values of the input parameters for the simulation model. The proposed approach, which involves extending data intelligence among a large amount of data to identify relevant relationships, and in the paper (Juta Pichitlamken, Barry L. Nelson, 2003) proposed an algorithm for optimization through modeling, when the performance indicator is evaluated using a stochastic simulation of discrete events, while changing the solution can depend on them deterministic constraints. In the paper (Juta Pichitlamken, Barry L. Nelson, 2003) considered the typical warehouse problems common to warehouse logistics, when the efficiency is provided by the best location of materials in the warehouse and the best routes of delivery. At work (Ramírez Ríos D., Ramírez Polo L., Jimenez Barros M., Castro Bolaño L., Maldonado Erik, 2013; Syrotenko A., Dachkovskyi V., \& Kopashynskyi S., 2021) consider typical warehousing problems that are common to warehousing logistics, when efficiency is ensured by the best location of material resources in the warehouse and the best transportation routes.

One of the parameters for the system of WME recovery is recovery time of damaged WME samples with different levels of complexity. On this basis, it is necessary to determine the rational structure of WME recovery system and the structure, composition of forces and means of the WME recovery system at each level of the hierarchy.

Therefore, the purpose of this article is to develop a model of the process of recovery of WME in a special period, taking into account the peculiarities of the occurrence and accumulation of the volume of tasks for the recovery of WME. 


\section{Results and discussion}

Analysis of peculiarities of functioning of the WME recovery system in conditions of a special period indicates the need to consider adjusting the structure of the logistics system of the Armed Forces of Ukraine, which would take into account the specifics of the emergence and accumulation of the volume of tasks for the WME recovery. The results of the synthesis of the logistics system of the Armed Forces of Ukraine are the initial data for the formation of recommendations to build up the forces and means of the base version of the WME recovery in a special period (Havryliuk, I. Matsko, O. Dachkovskyi V., 2019).

The main parameter for the WME recovery system is the acceptable time of WME recovery, which is differentiated by the level of complexity of the WME recovery tasks. The calculation of such parameter for the basic variant of construction of WME recovery system can be made using the average index of intensity of the flow of possible volumes of tasks on WME recovery, which is acceptable enough to study the functioning of the system on long time intervals (Dachkovskyi, V. Strelbitskyi, M., 2020).

This assumption implies the possibility of taking the flow of service requests as a constant value, and the service time of each request distributed according to the exponential law. This means that the required value of service time for each service request $\tau$ can be calculated based on the use of finite relations of the Erlangian mass service theory by solving the equation (Pavlovsky, O.V., 2015)

$$
\mathrm{T}_{\text {прд }}=f(\tau, \lambda)
$$

where $\mathrm{T}_{\text {прд }}$ - maximum allowable time of the request in the service system;

$\lambda$ - intensity of the flow of demands for service.

It should be noted that for a special period, as combat experience indicates, such an assumption is not always acceptable, because the enemy defeats WME samples in general during combat operations. In between battles, types of WME may be damaged by subversive reconnaissance groups (DRGs), robotic means (complexes) (unmanned aerial vehicles (UAVs), ground robotic complexes (GRCs)) detonation of explosive objects and failure of operational malfunctions.

The accepted assumption about the character of the occurrence of the volumes of the WME recovery tasks under the conditions of the special period allows us to accept the function of the intensity of the flow of the WME recovery tasks in the form, $\left[0, T_{1}\right]$-combat time interval, $\left[T_{1}, T\right]$ - time interval between battles (Ventzel E.S., Ovcharov L.A., 1983).

The physical content of this dependence is that the bulk of the volume of WME recovery tasks appears at time $T_{1}$ (combat mission time), during the rest of the time interval $\left[T_{1}, T\right]$, the amount of time remaining before the next combat mission, the intensity of the volume of WME recovery tasks on behalf of the group of troops decreases sharply.

To determine the value $\tau$ under the specified assumption about the type of function $\lambda(t)$, we apply a method based on the definition of some non-random function that does not decrease, which would limit with a given probability $R(\tau)$ all possible realizations of the function of accumulation of the volume of tasks for the restoration of WME in time

$$
v(t)=\int_{0}^{t} \lambda(\mathrm{x}) d x, t, x \in[0, T]
$$

If the system of the mass service (SMS) will provide timely service requirements with the law of their accumulation to the input of the form $n(t)$, then in this case with the probability $R(\tau)$ is guaranteed service and for all other possible realizations $v(t)$.

Assuming that the flow of demands for service with parameter $\lambda(t)$, which has the properties of ordinality and lack of consequence, determine the probability of arrival of some number $K$ of demands to the input of the service system in the time interval $[t, t+\Delta t]$ 


$$
\vartheta_{\mathrm{K}}(t, t+\Delta t)=\frac{[v(t+\Delta t)-(t)]^{k}}{k !} \exp \{-[v(t+\Delta t)-v(t)]\}, k=1,2 \ldots t, x \in[0, T]
$$

and consider the problem of constructing a $n(t)$ with integer values in the interval $[0, T]$ piecewise constant non-decreasing function

$$
n(t)=n_{j}, \text { при } t_{j}<t<t_{j+1}, j=0,1,2, \ldots m, n_{j} \leq n_{j+1}, t_{0}=0, t_{m+1}=T
$$

Suppose that dependence (3) is given. Let us find the probability of realization of the inequation

$$
v(t) \leq n(t), t \in[0, \mathrm{~T}]
$$

Let $A-$ be an event consisting in the fulfillment of an inequality (4). Let us introduce the events $A_{k 0}, k_{1}, \ldots k_{m}$, the realization of which means the fulfillment of the system of equations: $v\left(t_{j-0}\right)=k\left(t_{j-1}\right) j=0,1,2, \ldots, m$, $k_{j-1} \leq k_{j}$. If the sets of numbers $k_{0}, k_{1}, \ldots, k_{m}$ do not coincide (differ from each other by at least one term), the events $A_{k 0}, k_{1}, \ldots k_{m}$ by these sets are incompatible. Event $A$ is a combination of these events over all heterogeneous sets $k_{0}, k_{1}, \ldots k_{m}$. Then the probability of the event $A$ can be determined by the formula

$$
P(A)=\sum_{k_{J-1} \leq k_{J} \leq n_{j}} P\left(A_{\mathrm{k} 0}, \mathrm{k}_{1}, \ldots, \mathrm{k}_{m}\right), j=0,1,2, \ldots, m, k_{j-1}=0
$$

Event $A_{k 0}, k_{1}, \ldots k_{m}$ consists in the from each other events (according to the simultaneous realization $m+1$ of independent hypothesis of no-sequence)

$$
v\left(t_{j+1}-0\right)-v\left(t_{j}+1\right)=k_{j}-k_{j-1}, j=0,1,2, \ldots, m, k_{j-1}=0
$$

The probability of each of them will be $\vartheta_{k_{j}-k_{j-1}}\left(t_{j}, t_{j+1}-0\right)$, then

$$
P\left(A_{k_{0}, k_{1}}, \ldots, k_{m}\right)=\prod_{j=1}^{m} \vartheta_{k_{j}-k_{j-1}}\left(t_{j}, t_{j+1}-0\right)
$$

Substituting sequentially (2) in (6) (under $k=k_{j}-k_{j-1}, t=t_{j}, \Delta t=t_{j+1}-t_{j}$ ) and (6) in (5), get

$$
P(A)=e^{-\bar{n}} \sum_{k_{m}=0}^{\mu_{m}} \sum_{k_{m-1}=0}^{\mu_{m-1}} \ldots \sum_{k_{0}=0}^{\mu_{0}} \prod_{j=0}^{m} \frac{\Delta v_{j}^{k_{j}-k_{j-1}}}{\left(k_{j}-k_{j-1}\right)}
$$

where

$$
\begin{gathered}
\bar{n}=v(T)=\sum_{j=0}^{m} \Delta v_{j}, \Delta v_{j}=\int_{t j}^{t j+1} \lambda(x) d x \\
\mu_{0}=\min \left(n_{0}, k_{1}\right) \\
\mu_{m-1}=\min \left(n_{m-1}, k_{m}\right) \\
\mu_{m}=n_{m}
\end{gathered}
$$

Thus, to solve the problem we need to determine the values $t_{j}, n_{j}, m$ under the condition $P(A) \geq R(\tau)$.
By the time $t$ before entering the recovery system $v(t)$ demands are received. The system of the mass service can still serve at least $\frac{t}{\tau}$ 
requests. The time of the claim in the recovery system will not exceed the allowable time $T_{\text {прд }}$

$$
l(t)=\frac{t+T_{\text {прд }}}{\tau} \geq v(t), t \in[0, T]
$$

Hence, for a given value, $\tau$ as a dependency, $n(t)$ only those of (3), that satisfy the conditions

$$
\frac{T}{\tau} \geq n(T) ; \frac{t+T_{\text {прд }}}{\tau} \geq n(t) .
$$

The value of $T_{\text {прд }}$ can be determined by the known value of the intervals $[0, T]$ and the given

$$
n^{*}(t)=\max \{n(t), n(t), \ldots\} \leq \frac{t+T_{\text {прд }}}{\tau}, n^{*}(T)=\frac{T}{\tau}
$$

The levels $n_{j}$, time moments $t_{j}$ and the number $m$ can be determined by the formulas:

$$
n_{j}=n_{0}+j, n_{0}=\frac{T_{п р \partial}}{\tau}, j=0,1,2, \ldots, m, m=\frac{T}{\tau}-n_{0}, t_{j}=\left(n_{0}+j\right) \tau-T_{п р \partial} .
$$

When applying the numerical method, it is necessary to develop some hypothetical WME recovery system and determine the set of parameters $x_{k}, k \in \overline{1, k^{*}}$, characterizing the structure of construction of the WME recovery system and functioning. After that, carry out the selection of the performance indicator of the recovery system optimized $W$ where the functional dependence $W\left(x_{1}, x_{1}, \ldots, x_{k^{*}}^{*}\right)$ is stabilized.

To determine the optimal system is required to find a vector $X^{*}=\left(x_{1}^{*}, x_{2}^{*}, \ldots, x_{k}^{*}\right)$, , at which the efficiency of the system takes the maximum (minimum) value.

Then $X^{*} \sim W^{*}$ gives the optimal combination of system parameters to be found. The problem domain of the function can be defined by the set of allowable vectors $x k \overline{1, k^{*}}$ kmax $_{\text {kmin }}$. The search for the optimal combination of system parameters can be performed either by directed statistical search or by dynamic programming. Let's consider the process of applying the method of directed statistical search as more acceptable for solving the formulated problem of the optimization WME recovery system.

As you know, the idea of directional statistical search is that in the space of optimizable parameters an $i$-th step in a random direction is made $\xi$. If the value of the function in the new state $W\left(X_{i+1}\right)$ is greater (we assume that the maximum of this function is determined) than the value of $W\left(X_{i}\right)$ in the initial state, then the step is repeated in the same direction $\xi$. If the value of the function in the new state $W\left(X_{i+1}\right)$ has not increased, the system returns to the previous state, from where a new search step in a new random direction is made.

There are several varieties of statistical search algorithms for optimizing complex systems (Ventzel E.S., Ovcharov L.A., 1983; Pavlovskyi, O. Mazur, V. Tarhonskyi V., 2020; Sherstennykov Yu.V., 2017; Matsenko, V.G., 2014; Stetsenko I.V., 2010): statistical search algorithm by random punishment method, statistical search algorithm by best effort method; statistical search algorithm by statistical gradient method; global statistical search algorithm.

A simpler method from the point of view of practical use is a combined method for optimizing the WME recovery system, based on the use of the analytical method and the method of statistical modeling of the processes of functioning of complex systems. However, the application of this method is associated with the need to impose some restrictions on the character of changes in individual parameters of the system itself and the parameters that characterize the external conditions of its functioning.

The solution of the problem of determining 
the rational structure of the WME recovery system and calculating its main parameters by the combined method contains two steps.

At the first stage, based on the requirements to the permissible terms of WME recovery system, by analytical way we will determine the rational structure of WME recovery system as a whole.

At the second stage, using the method of statistical modeling, we calculate the main parameters of this system.

To solve the problem formulated at the first stage, let's first introduce the concept of the contour of the WME recovery system. This contour will be understood as a set of forces and technical means for the recovery of WME and the provision of material means, identical in their composition and capabilities. Also, the concept of heterogeneous incoming flow, in which requirements vary in complexity and the volume required to serve them, that is, the process of recovery of WME and the provision of material means. The occurrence of requirement $i$-th type $(\mathrm{i} \in \overline{1, k})$ in the flow has a probabilistic character, i.e. such an event as the arrival of $i$-th type, requirement in the WME recovery system occurs with a certain probability

$$
W_{i}\left(\sum_{i=1}^{k} W_{i}=1\right) .
$$

Taking into account the concepts introduced, to solve the problem at the first stage it is necessary to reduce it to the following statement: to determine what number of contours of the system of WME recovery should be; to determine what capacities of each of these contours (in terms of capabilities to meet the requirements of a certain type), at which the system of WME recovery will be able to provide the volumes of tasks of WME recovery in the required time (with the required productivity)

It should be noted that, in principle, the number of options for building a WME recovery system, each of which can meet the requirements for it, can be any large, but we will be satisfied only with those of them, the cost of creating which will be the lowest of all the options (Burimenko, Yu.I. Lebedeva, I.Yu. Shchurovskaya, A. Yu., 2016; Pavlenko P.M.,

\section{3; Yurov B.N., 1990).}

To solve this problem, we will use the method of variant synthesis (Stetsenko I.V., 2010; Burimenko, Yu.I. Lebedeva, I.Yu. Shchurovskaya, A. Yu., 2016; Pavlenko P.M., 2013; Yurov B.N., 1990; Tikhomirova A.N. Sidorenko, E.V., 2010), initially limiting the number of variants of construction of the WME recovery system, which is analyzed, rejecting the variants that clearly do not meet the proposed requirements to the capabilities of this system or are inexpedient in terms of financial costs.

If we consider the tasks of synthesis of the structure of WME recovery system, the elements of which are dispersed over a certain area of terrain, then we should also take into account in the calculations the fact that the applications in the incoming flow of volume of tasks of WME recovery differ not only in complexity and volume of service, but also in the value of the coordinates of their occurrence points relative to the coordinates of locations of means of repair of the WME recovery system. In other words, the task of servicing a twodimensional flow of demands arises. The presence of the second dimension leads ultimately to the fact that the allowable time of each scope of work in the recovery system $T_{\text {прд }}$ is reduced by some value $T_{\text {д }}$, equal to the time required for the arrival of the means of repair of WME to the place of execution of tasks. This, in turn, leads to the fact that the allowable service time for each service request (repair of WME of the volume of work) is reduced, which is equivalent, in the end, to increasing the requirements for the capabilities of the prospective WME recovery system. In this case, if condition $T_{\text {д }}=0$ is met, the structure of the WME recovery system would be ideal. However, the implementation of such a system becomes quite complicated, since this condition is realized only if there are sufficiently effective elements (means of technical reconnaissance, evacuation, repair of WME) of WME recovery system at each site that requires recovery. Such means should be able to perform the amount of work on the renewal of WME of any complexity (to serve any type of request). The other 
opposite of constructing an ideal system for the recovery of the WME is to create some universal means for the recovery of WME, the capabilities of which must be so great that the duration of each type of work does not exceed the value $T_{\text {прд }}$ for any value of $T_{\text {д }}$. The implementation of such a system also requires high cost, and in some cases (depending on the combination of $T_{\text {прд }}$ and $T_{\text {д }}$ values) it is, in accordance with the essence, not feasible. In this regard, it is necessary to define a certain intermediate option of building the WME recovery system (Stetsenko I.V., 2010; Burimenko, Yu.I.
Lebedeva, I.Yu. Shchurovskaya, A. Yu., 2016; Pavlenko P.M., 2013; Yurov B.N., 1990; Tikhomirova A.N. Sidorenko, E.V., 2010).

For the analysis, let's focus on three realistic options for the construction of multi-contour systems (Fig. 1).

At the first variant forces and means of each contour of WME recovery system allow to serve requests of any types, all contours of processes of functioning of WME recovery system are identical. The total flow of claims is evenly distributed across all contours $\left(\lambda_{1}=\lambda_{2}=\ldots=\right.$ $\left.\lambda_{n}=\lambda / n\right)$.

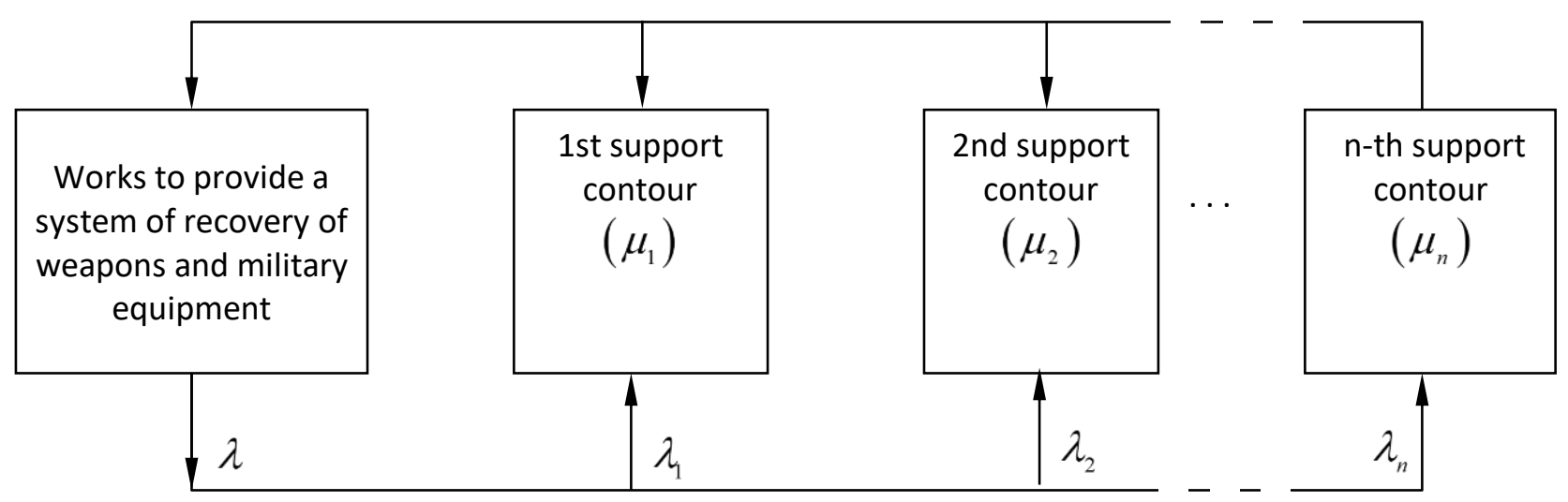

Figure 1 - Multi-contour WME recovery system

In the second variant, each contour of the WME recovery system is designed to serve requests of a certain type only. Requests for service to the input of the $l$-th contour are identical in type, and the intensity of their arrival is determined from the ratio

$$
\lambda_{l}=\lambda \alpha_{l}, \sum_{l=1}^{n} \alpha_{l}=1
$$

where $\alpha_{l}$ - coefficient characterizing the share of requests that can be serviced in the $l$-th contour of WME recovery.
In the third variant the forces and means of each contour allow to serve only certain kinds of requests, at that the number of kinds of requests, which can be served in each contour, increases as the number of contours of WME recovery system increases from $l=1$ to $l=n$. In this case intensity of requirements flow to the input of each of WME recovery contours can be calculated by the ratio (Burimenko, Yu.I. Lebedeva, I.Yu. Shchurovskaya, A. Yu., 2016; Pavlenko P.M., 2013; Yurov B.N., 1990)

$$
\begin{gathered}
\lambda_{1}=\lambda \alpha_{1}\left(1-\frac{\alpha_{1} T_{1}}{\sum_{l=1}^{n} \alpha_{l} T_{l}}\right) \\
\lambda_{2}=\lambda \alpha_{1} \frac{\alpha_{1} T_{1}}{(n-1) \sum_{l=1}^{n} \alpha_{l} T_{l}}+\lambda \alpha_{2}\left(1-\frac{\alpha_{2} T_{2}}{\sum_{l=1}^{n} \alpha_{l} T_{l}}\right), \\
\lambda_{n}=\lambda \alpha_{1} \frac{\alpha_{1} T_{1}}{(n-1) \sum_{l=1}^{n} \alpha_{l} T_{l}}+\lambda \alpha_{2} \frac{\alpha_{2} T_{2}}{(n-2) \sum_{l=1}^{n} \alpha_{l} T_{l}}+\ldots+\lambda \alpha_{l}+\frac{\alpha_{l} T_{l}}{(n-l) \sum_{l=1}^{n} \alpha_{l} T_{l}}+\ldots+\lambda \alpha_{n},
\end{gathered}
$$


where $T l, l \in \overline{1, n}$ - average service time of requests in the $l$-th WME recovery contour.

The requirements for the capabilities of each contour of the WME recovery system (intensity of service requests) can be determined from the ratio of the form (Stetsenko I.V., 2010; Burimenko, Yu.I. Lebedeva, I.Yu. Shchurovskaya, A. Yu., 2016; Pavlenko P.M., 2013; Yurov B.N., 1990; Tikhomirova A.N. Sidorenko, E.V., 2010):

for the first variant of construction of the WME recovery system

$$
\mu_{1}=\mu_{2}=\ldots=\mu_{n}=\frac{1}{n \tau} ;
$$

for the second variant of construction of the WME recovery system

$$
\mu_{l}=\frac{\alpha_{l}}{\tau}
$$

for the third variant of construction of the WME recovery system

$$
\mu_{l}=\frac{1}{T_{l}}, \quad \sum_{l=1}^{n} \mu_{l}=\frac{1}{\tau}
$$

Consequently, as $n$ increases, $T_{\mathrm{A}}$ and this eventually leads to a decrease in the required value of $\mu_{i}(n), \quad l \in \overline{1, n}$. However, the growth of the number of contours $n$ leads to the increase of expenses $\mathrm{C} \mu(n)$ for realization of each unit of productivity $\mu(n)$ at the expense of additional expenses connected with territorial dispersion (decentralization) of areas of fulfillment of works on recovery of WME.

To determine the optimum number of $n_{0}$ WME recovery contours in the WME recovery system at the $j$-th variant of its construction, $(j \in \overline{1,3})$ it is necessary to solve the equation of the form (Yurov B.N., 1990; Tikhomirova A.N. Sidorenko, E.V., 2010; Akhmetov R.R., 2011)

$$
\frac{d C_{j}(n)}{d n}=\frac{d\left[\sum_{l=1}^{n} C_{\mu}(n) \mu_{l}(n)\right]}{d n}=0 .
$$

Then, verify the execution of the inequality

$$
\left.\frac{d^{2} C_{j}(n)}{d n^{2}}\right|_{n-n_{0}}>0
$$

under condition $C\left(n_{0}\right)=\min _{j \in 1,3}\left\{C_{j}\left(n_{0}\right)\right\}$ and make a choice of the best option for the construction of the WME recovery system as a whole.

The next step is to solve the problem of the second stage, i.e. the task of calculating the basic parameters of the WME recovery system, which include parameters characterizing the structure and composition of forces and means of each contour of the WME recovery system (Dachkovskyi, V. Strelbitskyi, M., 2020; Pavlovskyi, O. Mazur, V. Tarhonskyi V., 2020; Matsenko, V.G., 2014; Stetsenko I.V., 2010; Burimenko, Yu.I. Lebedeva, I.Yu. Shchurovskaya, A. Yu., 2016).

Solving such a problem analytically is usually difficult, and in some cases impossible. As a consequence, there is a large number of mutual connections between heterogeneous contours, as well as between heterogeneous technical means of WME restoration within each contour.

In this regard, to solve problems of this type it is more appropriate to use the method of detailed or aggregate statistical modeling (Yurov B.N., 1990; Tikhomirova A.N. Sidorenko, E.V., 2010; Akhmetov R.R., 2011; Kolodizeva T.O., 2016). Let us consider a general approach to solving the second stage problem by the method of statistical aggregate modeling. To do this, let's specify the condition of the problem to be solved. Let's assume that according to the results of the solution of the first stage problem, a rational structure of the system of restoration of WME, which in general is a three-contour system, each contour of which can serve requests only of a certain type, while the contour with a higher order number can serve all types of requests. which can be served by any contour with a lower order number. The incoming stream in this system has requests of three types, differing from each other by the complexity and priority of the necessary work for their maintenance (Yurov B.N., 1990; Tikhomirova A.N. Sidorenko, E.V., 2010; Akhmetov R.R., 2011; Kolodizeva T.O., 2016).

$A$ variant of the aggregative model of such a system of restoration of WME is shown in Fig. 2 . 


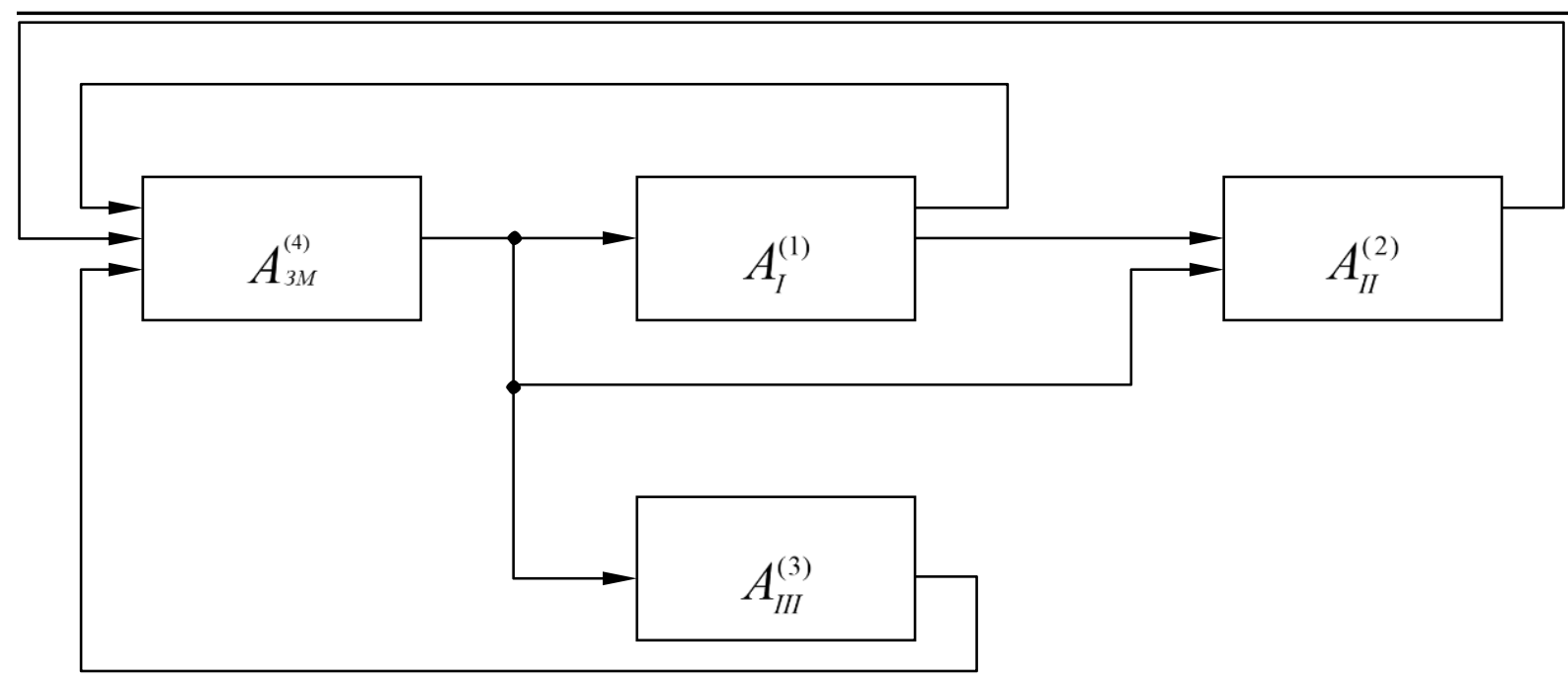

Figure 2 - Aggregative model of the WME recovery system

In Fig. 2 the aggregates $A_{I}^{(1)}, A_{I I}^{(2)}, A_{I I I}^{(3)}$, simulates the functioning of the contours of the system of recovery of WME, designed for the implementation of activities for the recovery of WME and the performance of works to provide material means of low, medium and high complexity.

The aggregate $A_{3 M}^{(4)}$ modulates the functioning of a set of means of recovery of WME and directly of WME damaged from enemy firepower, and the volume of tasks of recovery of WME of the appropriate complexity appears. At the input of each aggregate an input signal is received, which represents the set of parameters determining the nature of requests for the implementation of measures to restore WME. At the output of the aggregate, an output signal is formed that describes the parameters of serviced requests by forces and means of the WME recovery system, the simulated processes of functioning in this aggregate.

It is quite difficult to simulate the process of functioning of the system for the WME restoration when solving all the problems at the same time. It is more appropriate to model the processes of functioning of the aggregate system in each type of work of different complexity to be solved. Let's first consider the process of servicing requests in the WME recovery system when all or most aggregates are able to pass them (Matsenko, V.G., 2014; Stetsenko I.V., 2010; Burimenko, Yu.I. Lebedeva, I.Yu. Shchurovskaya, A. Yu., 2016; Pavlenko P.M., 2013). The structure of possible links in such a model is shown in Fig. 3.

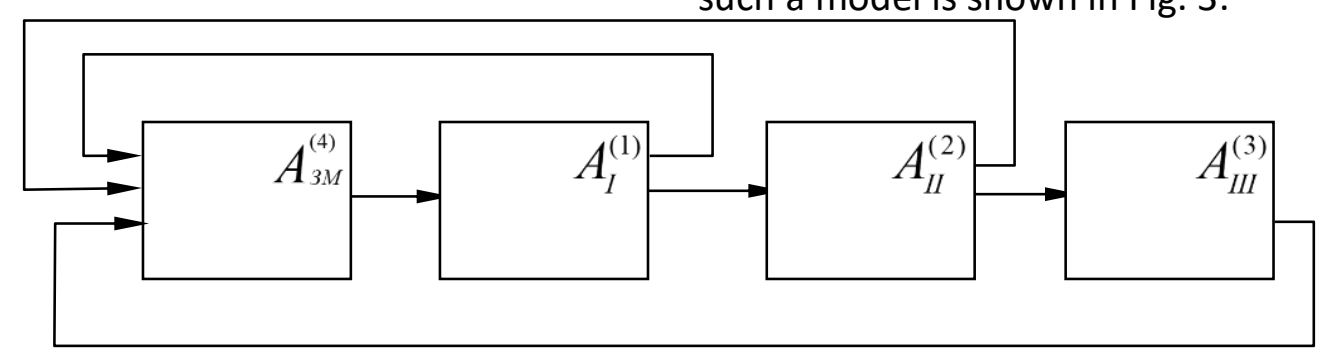

Figure 3 - Link structure in the aggregate model

The mathematical formalization of these connections can be represented as

$$
\eta(r, r+1)=\left\{\begin{array}{l}
1, \text { if there is a connection between therand }(r+1) \text { aggregates } \\
0, \text { If there is no connection }
\end{array}\right.
$$


where $r$ - aggregate number in the system $(r \in \overline{1, n})$.

This model allows us to describe the real links in the system for the restoration of WME, which consists of $l(l=\overline{1,3})$ contours, each of which is capable of performing $\gamma l$ different operations types for the restoration of WME and the execution of works to provide material means, according to $\gamma^{*} l$ requests for the performance of the volume of tasks for the restoration of WME. The total number of types of operations on the recovery of WME and the execution of works to ensure MM, carried out in the modeling system, is determined from the ratio

$$
\gamma=\sum_{l=1}^{3} \gamma l
$$

To formally describe the content of the links in the model under consideration, it is necessary to define for each aggregate included in the system the input and output signals.

The aggregate $A_{3 \mathrm{M}}^{(4)}$ can be considered as an external source, the output of which at the appropriate moment in time $t_{j}$ generates a signal forming a request to perform technical reconnaissance, evacuation, repair of damaged samples of WME, providing MM for repair of WME. In the general case we will assume that any application is characterized by the moment of issuance $t_{j}$ and $n$ parameters $\gamma_{1}, \gamma_{2}, \ldots, \gamma_{n}$. In other words, each bid is a vector of dimension $(n+1)$

$$
A_{3 \mathrm{M}}^{(4)}=\left(t_{j}, \gamma_{1}, \gamma_{2}, \ldots \gamma_{n}\right)
$$

The following parameters can be considered as output parameters of the aggregate $A_{3 \mathrm{M}}^{(4)}$ :

$\gamma_{1}$ - parameter that defines the group of operations available for execution in the 1st contour;

$\gamma_{2}$ - parameter that defines the group of operations available for execution in the 2nd contour;

$\gamma_{3}$ - parameter that defines the group of operations available for execution in the $3 r d$ contour.

In this case, it is considered that

$$
\gamma_{r}=\left\{\begin{array}{l}
1, \text { if the requests require the } r-\text { th group of works; } \\
0, \text { if not required }, r \approx k
\end{array}\right.
$$

The output signal of aggregate $A_{3 \mathrm{M}}^{(4)}\left(\mathrm{y}_{3 \mathrm{M}}^{(4)}\right)$ is the input signal for the aggregate $A_{I}^{(1)}\left(X_{I}^{1}\right)$. The transformation of the input signal $X_{I}^{(1)} n$ accordance with the algorithm of the aggregate $A_{I}^{(1)}$ functioning allows to obtain at the output of this aggregate the signal $\mathrm{y}_{I}^{(1)}$, which in turn is divided into several components that represent the input signals $X_{3 \mathrm{M}}^{(4)}$ and $X_{I I}^{(2)}$ for the aggregates $A_{3 \mathrm{M}}^{(4)}$ and $A_{I I}^{(2)}$ accordingly.

Determination of the $\underline{X}_{I I}^{(2)}$ component of the signal $\underline{y}_{I}^{(1)}$ can be done by the formula

$$
\underline{X}_{I I}^{(2)}=\underline{\mathrm{y}_{\mathrm{I}}^{(1) \theta(1,2)}}
$$

where $\theta^{(1,2)}=\left|\begin{array}{ll}1 & 0 \\ 0 & 0 \\ 0 & 0 \\ 0 & 1\end{array}\right|$ - address matrix between the 1 st and 2 nd aggregates

The addressability matrix has a $(r(x)+1)$ line and a $(r(y)+1)$ column. Here $r(y)-$ the number of parameters in the output signal from the aggregate $\mathrm{A}^{(r)}$, and $r(k)$ - the number of parameters in the input signal for the aggregate $\mathrm{A}^{(r+n)}$. Additional row and column take into account the moment of signal issuing and receiving (Matsenko, V.G., 2014; Stetsenko I.V., 2010).

Similarly, you can determine the data on the circulation of signals between other aggregates. To do this, you need to define address matrices for each of them 


$$
\theta^{(1,4)}=\left|\begin{array}{ll}
1 & 0 \\
0 & 1 \\
0 & 0 \\
0 & 0
\end{array}\right|, \theta^{(2,3)}=\left|\begin{array}{lll}
1 & 0 & 0 \\
0 & 0 & 0 \\
0 & 1 & 0 \\
0 & 0 & 1
\end{array}\right|, \theta^{(2,5)}=\left|\begin{array}{ll}
1 & 0 \\
0 & 1 \\
0 & 0 \\
0 & 0
\end{array}\right| \theta^{(3,4)}=\left|\begin{array}{ll}
1 & 0 \\
0 & 0 \\
0 & 1
\end{array}\right|
$$

The suggested formalization of the system of WME recovery in the form of an aggregative model is convenient for entering information about the interaction of contours into the electronic calculating machines and allows to establish the main connections in the WME recovery system, determine the circulation of signals between contours and study the quantitative relationships between the parameters characterizing service requests and service efficiency.

To analyze the dynamics of WME recovery system functioning, there are estimates of such characteristics as the probability of stay of a request serviced in the WME recovery system for the time not exceeding the specified one, or the number of requests serviced in the WME recovery system for the specified time, etc. It is convenient to represent it as a system of mass service. In this case, there is an opportunity to interpret the bodies of support of the system for the repair and recovery of WME and specialists to perform repair and recovery work as a set of models of stochastic systems of mass service. This interpretation is legitimate, because the process of performing certain technological operations for the recovery of WME and the performance of work on the provision of material resources is some process of maintenance. Therefore, the processes of recovery of WME in an operation (combat operations) can be seen as a process of servicing some set of requests for these works, coming from a finite number of sources. In this case the system of mass service is considered as multiphase. Each phase, which is the WME recovery system, is a multi-channel mixed not fully available mass service system with waiting (Burimenko, Yu.I. Lebedeva, I.Yu. Shchurovskaya, A. Yu., 2016; Pavlenko P.M., 2013; Yurov B.N., 1990; Tikhomirova A.N. Sidorenko, E.V., 2010).

In particular, the aggregate model shown in Fig. 3, can be regarded as a multiphase service system consisting of phases $r(r=1,2, \ldots, n)$. Each aggregate of the system is then interpreted as one phase. Aggregate $A_{3 M}^{(4)}$, from where the requests to the WME recovery system come and where they go after the end of service, can be considered as phase zero $(j=0)$. For the practical construction of the multiphase model it is necessary to interpret each phase accordingly a mass service system, the class of which is predetermined by the character of functioning and the tasks of the technical means simulated in this phase.

The input information for each phase must be:

- the sequence number of the mass service system phase;

- the number of directions of convergence of signals to the input of each phase with the number $r: u_{c r}=1,2, \ldots, u^{*}{ }_{c r}$ (in this case $u_{c 1}=$ $1, u_{c 2}=1, u_{c 3}=1$ );

- the direction of each ascent before the phase with an ordinal number $r ;\left(r-u_{c r}, r\right)$ (in this case $\left.1-u_{c 0,1}, 2-u_{c 1,2}, 2-u_{c 2,3}\right)$;

- the number of divergence directions after the $r$-th phase: $u_{p 2}=1,2, \ldots, u_{p 3}^{*}$ (in this case $u_{p 1}=2, u_{p 2}=2, u_{p 3}=1$ );

- the direction of each divergence after the phase with ordinal number $r:(r+u(r) p)$ (in this case $1+u_{p 0,1} ; 1+u_{p 2,1} ; 2+u_{p 0,2} ; 2+$ $\left.u_{p 3,2} ; 3+u_{p 0,3}\right)$;

- a set of targeting matrices.

The above information is necessary to prepare the $r$-phase model for a group of measures to take into account the specifics of its functioning in terms of the classification of WME elements (Burimenko, Yu.I. Lebedeva, I.Yu. Shchurovskaya, A. Yu., 2016; Pavlenko P.M., 2013; Yurov B.N., 1990; Tikhomirova A.N. Sidorenko, E.V., 2010). In this case, each phase is characterized by an appropriate set of parameters, depending on the character of the chosen model. When modeling the operation of each subsequent contour of the system, except 
one, it is necessary to take into account the flow of un-served by the preliminary contour requests of appropriate complexity.

The modeling of the functioning of the 1st and 2 nd phases is determined by the duration of the intervals $\left[0, T_{\mathrm{M}}\right]$. The simulation of the operation of the 3rd phase of the WME recovery system is completed with the end of service of all requests from the incoming flow of the previous phases.

To assemble a model of the WME recovery system according to (Sherstennykov Yu.V., 2017; Matsenko, V.G., 2014; Stetsenko I.V., 2010; Burimenko, Yu.I. Lebedeva, I.Yu. Shchurovskaya, A. Yu., 2016; Pavlenko P.M., 2013; Yurov B.N., 1990; Tikhomirova A.N. Sidorenko, E.V., 2010) it is necessary to vary:

- characteristics of application flows for works of different complexity (1st contour Conclusions

In order to explain the distribution of tasks between the levels of the system for the recovery of weapons and military equipment, the method of aggregate modeling was used, by which the system for the recovery of weapons and military equipment was represented in the form of a multicontour system. Three variants of structure with appropriate functional distribution and service intensity parameter were considered. As a result of the study, the rational number of contours of WME recovery multi-channel mass service system with a limited queue length and the ability to perform I-level complexity; 2nd contour - multi-channel mass service system with a limited queue length and the ability to perform I-level and II-level complexity; 3rd contour - multi-channel mass service system without restrictions and the ability to perform works of any complexity);

- the degree of damage received by the samples of WME, which reduces the intensity of work on the recovery of WME;

- data on the intensity of work on the recovery of WME of different types and complexity.

It is shown that the system of recovery of WME should be three-tiered, the forces and means of the first level should refer to the military level, the second to the operational level, and the third to the strategic level.

system has been confirmed and connectivity and addressability matrices between the contours of the system have been developed.

The further research may be based on the provisions of the theory of mass service and the method of aggregative modeling, the development of recommendations for the distribution of functional powers between the subjects of the implementation of the processes of recovery of weapons and military equipment.

\section{References}

Akhmetov R.R. (2011). Fundamentals of Logistics of Troops: Study Guide. Omsk: SibADI, p. 152

Better, M. Glover, F. Laguna M. (2007). Advances in analytics: Integrating dynamic data mining with simulation optimization. IBM J. RES. \& DEV. Vol. 51 No. 3/4 p. 477-487.

Bilous M.V., Shmatenko O.P., Galan O.V. (2020). Theoretical aspects of using logistics outsourcing in the organization of medical supply of the Ukrainian Armed Forces. News of pharmacy. № 2 (100). p. 77-83. https://doi.org/10.24959/nphj.20.35

Bondarenko O.G., Tovma L.F., Nesterenko R.V., Kasim O.G. (2018). Basic provisions on logistics of the National Guard of Ukraine. Bulletin of Transport Economics and Industry № 61. p. 230-240.

Burimenko, Yu.I. Lebedeva, I.Yu. Shchurovskaya, A. Yu. (2016). Optimization methods and models for solving problems on a computer: textbook. allowance. Odessa, $152 \mathrm{p}$.

Dachkovskyi, V. $\left(2020^{\mathrm{a}}\right)$. Formalization of problem and justification of the set of principles of construction of the system of restoration of weapons and military equipment. Journal of Scientific Papers "Social Development and Security», 10(4), 128-138. DOI: 10.33445/sds.2020.10.4.12 Dachkovskyi, V. (2021). Methods of evaluation 
of efficiency of logistic operations. Journal of Scientific Papers "Social Development and Security", 11(1), 179-196. DOI: 10.33445/sds.2021.11.1.17

Dachkovskyi, V. Strelbitskyi, M. (2020). Mathematical model of system functioning restoration of weapons and military equipment. Modern Information Technologies in the Sphere of Security and Defenc, № 2(38) p. 87-94.

Dachkovskyi, V.O. $\left(2020^{\mathrm{b}}\right)$. The method of the optimization of material flows for functioning of the recovery system. Social development \& Security. №10(2), p. 27-34.

Dyptan V., Tykhonenko O., Pavlenko S. (2020). Methodological assessing efficiency of material support of actions of aviation units and armed forces units of Ukraine. Honor and law. № 4 (75). p. 10-17.

Havryliuk, I. Matsko, O. Dachkovskyi V. (2019). Conceptual basis of flow management in the system of logistic support of the armed forces of Ukraine. Modern Information Technologies in the Sphere of Security and Defence. № 1(34), p. 37-44

Juta Pichitlamken, Barry L. Nelson (2003). A combined procedure for optimization via simulation. ACM Transactions on Modeling and Computer Simulation, Vol. 13, No. 2, p. 155-179

Kolodizeva T.O. (2016). Supply Chain Management: a textbook Kharkiv: KhNEU. S. Kuznets, $164 \mathrm{p}$.

Kondratyuk, I. (2021). Analysis of the development of mobile maintenance and repair of military vehicles. Journal of Scientific Papers "Social Development and Security", 11(1), 52-69. DOI: 10.33445/sds.2021.11.1.6

Kotsiuruba, V. Dachkovskyi V. (2020). Method of evaluation of efficiency of functioning of arms and military engineering system. "Modern Information Technologies in the Sphere of Security and Defenc". № 1(37) C. 514.

Kotsyuruba, V., Sivak, V., \& Uhrynovych, O. (2021). Methodical approach for formulating requirements for the restoration system of armaments and military equipment. Journal of Scientific Papers "Social Development and Security», 11(4), 158-168. DOI: 10.33445/sds.2021.11.4.14

Kucheruk O.O., Polyakov A.P. Purpose and types of military road transport. Available from: https://conferences.vntu.edu.ua/index.php/ all-fmt/all-fmt-2020/paper/download/ 9727/8089.

Matsenko, V.G. (2014). Mathematical modeling: a textbook. Chernivtsi: Chernivtsi National University. $519 \mathrm{p}$.

NATO Logistics Handbook. 2012. p. 256.

Nestorenko A. (2014). Mathematical modeling of the logistics of industrial enterprises with different options for basic information. Technology audit and production reserves. № 5/1(19), p. 69-75.

Pavlenko P.M. (2013). Fundamentals of mathematical modeling of systems and processes: a textbook. Kyiv: Book edition of NAU, $201 \mathrm{p}$.

Pavlovsky, O.V. (2015). Forecasting the magnitude of losses of weapons and military equipment during operations (combat operations). Weapons systems and military equipment. № 4. P. 116-118. Available from: http://nbuv.gov.ua/UJRN/soivt_2015_4_33.

Pavlovskyi, O. Mazur, V. Tarhonskyi V. (2020). Methodical approach to substantiation of the composition of repair divisions for restoration of body technique of the operational group of Visa. Modern Information Technologies in the Sphere of Security and Defence. № 2(38), p. 119-124.

Ramírez Ríos D., Ramírez Polo L., Jimenez Barros M., Castro Bolaño L., Maldonado Erik. (2013). The design of a real-time warehouse management system thatintegrates simulation and optimization models with RFID technology. The International Journal of Computer Science \& Applications (TIJCSA). Vol. 2. No. 04. p. 18-37.

Saleh Alyahya, Ashit Kumar Dutta (2020). Optimizition of an RFID-Enabled Networks using Fuzzy Logic Technique. International Journal of Advanced Science and Technology. Vol. 29, No. 03, p. 9274-9288. 
Sampir, O. (2021). Improved methods for assessing the system of weapons and military equipment recovery of a separate mechanized brigade. Journal of Scientific Papers "Social Development and Security", 11(5), 165-178. DOI: $10.33445 /$ sds.2021.11.5.16

Sampir, O. (2021). Improvement of the method of determining opportunities for technical exploration of damaged samples of weapons during combat. Journal of Scientific Papers "Social Development and Security", 11(2), 141-151. DOI: 10.33445/sds.2021.11.2.14

Sherstennykov Yu.V. (2017). A Simulation Model of the Logistics System of a Small Enterprise. Problems of the economy № 1, p. 457-466.

Stetsenko I.V. (2010). Systems modeling: a textbook. Cherkasy: ChTTU. 399 p.

Syrotenko A., Dachkovskyi V., \& Kopashynskyi S. (2021). Methodological pidhid before rational vibor mists ta kilkosti polovikh warehouses with material foods. InterConf. Available from: https://ojs.ukrlogos.in.ua/index.php/interco nf/article/view/9928

Tikhomirova A.N. Sidorenko, E.V. (2010).
Mathematical models and methods in logistics: A textbook. Moscow: NIAU MEPhI, 320 p.

Ventzel E.S., Ovcharov L.A. (1983). Applied problems of probability theory. Moscow: Radio and communication, $416 \mathrm{p}$.

Yurov B.N. (1990). Operations Research. Moscow: VIA, $528 \mathrm{p}$.

Zalevsky G., Lekakh A., Gurin O., Startsev V., Kalachova V. (2019). Indicators and criterias of general points of the methodologu ofestimativu efficiency of the implementationof logistic support ofthe military units of the air force of the armed forces of ukraine in the armed warfare. Collection of scientific works of Kharkiv National University of the Air Force. № 3(61) c. 45-52.

Zvonko, A., Ovcharenko, I., Yaroshenko, A., \& Pavlov, D. (2021). Methodical approach to determining the possibilities of the weapon restoration system and military equipment for technical intelligence. Journal of Scientific Papers "Social Development and Security», 11(5), 146-154. DOI: 10.33445/sds.2021.11.5.14 